\title{
ESTRUTURAS DE GOVERNANÇA, COOPERAÇÃO E LEGITIMIDADE NA CONSTRUÇÃO DO DESENVOLVIMENTO REGIONAL NO INTERIOR DO ESTADO DE SÃO PAULO: ALGUMAS NOTAS PRELIMINARES
}

\author{
GOVERNANCE STRUCTURES, COOPERATION AND \\ LEGITIMACY IN THE CONSTRUCTION OF \\ REGIONAL DEVELOPMENT IN THE INTERIOR OF \\ THE STATE OF SÃO PAULO: SOME PRELIMINARY \\ NOTES
}

Wilson Bento Figueiredo Filho

Academia da Força Aérea - SP - Brasil

\begin{abstract}
Resumo: Este artigo é baseado nos resultados parciais de uma pesquisa que busca relacionar desenvolvimento sustentável regional e estruturas de governança no interior do Estado de São Paulo. A busca pelo desenvolvimento sustentável regional é tarefa complexa que obriga os vários atores interessados nesse assunto à cooperação. No entanto, a cooperação no âmbito das estruturas é limitada pelas influências postas pelos contextos mundial e brasileiro. Fundamentado na coleta de dados secundários e nas entrevistas que sustentam os resultados parciais da pesquisa, o artigo tem por objetivo propor uma possível explicação a partir dos conceitos de atores sociais, instituições e legitimidade.
\end{abstract}

Palavras-chave: Instituições. Atores sociais. Participação. Consciência do risco. Patrimonialismo.

Abstract: This article is based on the preliminary results of a survey that seeks to relate regional sustainable development and governance structures in the state of São Paulo. The search for sustainable regional development is a complex task that requires various stakeholders to cooperate in this matter. However, in the state of São Paulo, cooperation is limited by the influences posed by worldwide and brazilian contexts. Based on secondary data and interviews, the article proposes a possible explanation to the concepts of social actors, institutions and legitimacy.

Keywords: Institutions. Social Actors. Participation. Risk awareness. Patrimonialism.

\section{Introdução}

O presente trabalho faz parte de uma pesquisa ${ }^{1}$ que procura caracterizar as estruturas de governança (os arranjos produtivos locais, os comitês de bacias

\footnotetext{
1 O grupo de pesquisa "Estruturas de governança e desenvolvimento territorial" desenvolve o projeto pesquisa intitulado "Modalidades da governança territorial no estado de São Paulo" financiado pela FAPESP (processo 11/50837-9), sob a coordenação do Prof. Dr. Elson L. Pires do Departamento de Planejamento Regional - DEPLAN - da UNESP, campus Rio Claro. Participam dessa pesquisa, além do autor deste artigo, os seguintes pesquisadores: Adriana Renata Verdi (APTA), Lucas Fuini (UNESP - Ourinhos), Maria Célia de Souza (IEA), Malimiria Otani (IEA), Nelson Staud (IEA - in memorian), Rodrigo Furgieri Mancini (Aequitas), mais os estagiários José Rubens Guido Junior, Ricardo Nagliati Toppan e José Renato Ribeiro.
} 
hidrográficas, os circuitos turísticos e as câmaras setoriais) presentes no interior do Estado de São Paulo e sua contribuição para o desenvolvimento regional sustentável.

As discussões dentro do grupo de pesquisa apontam para algumas dificuldades no funcionamento dessas estruturas no que se refere ao desenvolvimento regional sustentável. Entre elas, destaca-se a questão da cooperação entre os atores. Estes últimos pensam e agem com vistas a um objetivo a partir de um sistema de regras, as instituições, que determinam o que é legítimo. Assim, as dificuldades em cooperar são analisadas a partir das interrelações entre três conceitos: atores ou organizações, instituições e legitimidade.

A busca pelo desenvolvimento sustentável em âmbito regional é tarefa complexa que obriga os vários atores sociais interessados no assunto à cooperação. Os governos federal, estadual e municipal, câmaras de vereadores, agências de fomento, partidos políticos, sindicatos, empresas, universidades, organizações não governamentais de diversos tipos e organizações associativas não têm os recursos cognitivos, gerenciais, econômicos e políticos para enfrentar sozinhos os desafios impostos pelo desenvolvimento sustentável. São obrigados à cooperação, numa espécie de jogo, cujo prêmio - sempre passageiro - é o topo de uma hierarquia flexível que o habilita a dirigir, ao menos em parte, as ações ou reações relativas ao desenvolvimento sustentável regional (FIGUEIREDO, 2012).

Entretanto, há dificuldades em cooperar que podem ser atribuídas às influências dos contextos mundial e brasileiro. As primeiras dizem respeito ao esgotamento do modelo de desenvolvimento baseado na indústria de massa e percebido pela crescente incapacidade em lidar com suas várias consequências, o que Beck (2003) chama de consciência do risco que, por sua vez, estimula o aumento da participação.

As influências do contexto brasileiro são caracterizadas pelo patrimonialismo ainda presente no Estado nacional, que torna a sua ação menos eficaz; e pela "incompletude do Estado", para utilizar a expressão cunhada por O'Donnel (1998, p. 46), e percebida pela parcialidade das leis, o que resulta em aumento da incerteza nas relações sociais.

A consciência do risco e o aumento da participação podem se manifestar regionalmente no encaminhamento das externalidades negativas. Encaminhamento que pressupõe negociações entre atores que atuam em âmbito regional. É justamente nesse ponto que o patrimonialismo e a "incompletude da lei" dificultam a cooperação.

Nesse sentido, a hipótese incial do presente trabalho pode ser expressa através da seguinte afirmação: mesmo dentro das estruturas de governança que funcionam no Estado de São Paulo, a cooperação entre atores é limitada porque as influências dos contextos mundial e brasileiro tendem ao conflito.

Para desenvolver as ideias postas até aqui, este trabalho é dividido em seis seções, contando com esta introdução. Na segunda seção, são estabelecidas as definições iniciais de atores sociais ou organizações e instituições, bem como a relação de ambos com o conceito de legitimidade. Na terceira seção, são 
apresentadas as influências postas pelo contexto mundial e seus impactos sobre instituições e atores. A seção quatro repete o mesmo padrão, mas tratando das influências do contexto brasileiro. Na seção cinco, é estabelecido como as influências dos contextos mundial e brasileiro são percebidas em âmbito regional e como elas impactam o funcionamento das estruturas de governança identificadas pelo grupo de pesquisa. Finalmente, nas considerações finais, há um pequeno apanhado das ideias propostas ao longo do texto.

\section{Atores sociais ou organizações, instituições e legitimidade}

Para De Bruyne, Herman, Schoutheete (1997), uma teoria pode ser descrita como um conjunto de proposições que contém conceitos que fazem referências empíricas ao real. Ela tem dois aspectos fundamentais: o conceitual e o de formulação lógica. O primeiro refere-se aos "conceitos cuja compreensão deve ser intersubjetivamente 'evidente', essa compreensão é possível por referência ao contexto semântico da teoria" (DE BRUYNE, HERMAN, SCHOUTHEETE, 1997, p. 110). É nesse sentido que nos próximos parágrafos são estabelecidos os conceitos de atores e organizações e se explica que ambos se referem ao mesmo fenômeno posto pela realidade; bem como a ligação entre aqueles e os conceitos de instituição e de legitimidade.

Buckley (1971) utiliza o conceito organização para explicar de maneira geral o funcionamento de uma sociedade, uma empresa ou um hospital. Em comum, todas são formadas por grupos de indivíduos que pensam e agem para atingir algumas metas a partir de diferentes graus de coerção e de liberdade. Neste sentido, uma organização pode ser descrita como um ambiente transacional no qual "inúmeros acordos são continuamente firmados, renovados, revogados, revisados" (BUCKLEY, 1971, p. 215). A consequência é a constante revisão da cultura ou da ordem organizacional, o que gera tensão interna e com as demais organizações.

Dubar (2004) preocupa-se com as diferentes interpretações teóricas que os sociológos franceses dão a respeito do individuo e da sua relação com o social. Propõe que os conceitos de agente, ator, sujeito e autor implicam em diferentes concepções das relações sociais. O pesquisador que adota o conceito ator tem uma concepção estratégica das relações sociais, ou seja, elas ocorrem entre vários grupos de indivíduos, dentro de um contexto organizacional, que são capazes de aproveitar oportunidades, isto é, têm capacidade de desenvolver estratégias que mudam conforme a sua situação dentro daquele contexto. $O$ ator é um "constucto" humano feito e organizado para atingir determinados fins que se relaciona com outros atores com vistas a concretizar sua meta. A competição ou a cooperação ocorrem em função da situação dos atores interessados na mesma meta ou metas afins.

Matus (1996) assume que governos, empresas, universidades, sindicatos, asscoiações diversas, partidos políticos, centros de pesquisa, etc., são atores porque controlam e manipulam recursos econômicos, políticos, cognitivos e 
gerenciais para atingir certo objetivo. As relações entre atores podem ser descritas como um jogo, no qual eles pensam e agem de maneira estratégica para acumular aqueles recursos e, desta maneira, anular opositores ou atrair aliados, sempre visando dado objetivo.

Quer utilizem o conceito "organização", quer utilizem o conceito "ator", os três autores brevemente citados (BUCKLEY, 1971; DUBAR, 2004; MATUS, 1996) referem-se a grupos de indivíduos com um objetivo, que se relacionam com outros grupos. Nesse caso, tais conceitos podem designar governos em suas diversas esferas, partidos políticos, empresas, sindicatos, organizações não governamentais, organizações associativas, universidades, etc. Todos esses atores ou organizações pensam e agem para concretizar seus objetivos que, em algumas ocasiões, podem ser convergentes e, em outras, divergentes. Adotam, por conseguinte, comportamentos estratégicos que variam conforme a situação.

Os conceitos de organização ou atores não se confundem com o conceito de instituição, as regras do jogo. Para North (1993), os atores ou organizações podem ser definidos como grupos de indivíduos enlaçados por identidade ou objetivos comuns, que agem a partir de um propósito deliberado em consequência das oportunidades criadas pelas instituições. Surgem em função dessas estruturas que dão forma e limitam a interação humana, seja ela de caráter político, econômico ou social. Para o autor em questão: "el propósito de las reglas es definir la forma que o juego se desarrolará. Pero el objetivo del equipo dentro del conjunto de reglas es ganar el juego [...]" (NORTH, 1993, p. 15).

Mas, diferente do que ocorre em um jogo lúdico, as regras do jogo social não estabelecem a igualdade de condições iniciais. Pelo contrário. Cada ator parte de uma base histórica pré-acumulada de recursos, que torna a quantidade, a qualidade e o manejo dos recursos diferentes para cada um deles (MATUS, 1996). Nesse mesmo sentido, Marques (2006) diz que há atores com melhor acesso a recursos ou são melhor preparados para utilizar os recursos diponíveis e, por isso, na maioria das situações, alguns resultados são mais prováveis que outros.

Català (1997) sustenta que as instituições articulam a interação entre atores sociais e expressam as relações de poder e interesses dentro de dada sociedade. São os resultados da aprendizagem social e não podem ser mudadas por decreto. Já as organizações ou atores sociais são classificados como "realidades concretas". "Son ordenaciones de recursos concretos y discretos (humanos, finacieros, técnicos) para la consecución de objetivos" (CATALÀ, 1997, p. 17). Sua criação e mudança ao longo do tempo são diferentes do processo de criação e mudança das instituições, ambos os processos são mais lentos no caso destas últimas.

As instituições, de acordo com Buckley (1971), não determinam pensamento e ação, são regras mais ou menos gerais que, no entanto, não especificam o funcionamento do sistema " $[. .$.$] na realidade encontramos uma$ grande quantidade de dissenso, ambiguidade, conflito e mudanças nas regras operatrizes da estrutura social" (BUCKLEY 1971, p. 231). O conceito de legitimidade, no sentido de adesão espontânea, deve estar associado ao conceito de instituição quando este é usado para definir as normas e valores que se 
traduzem em regras estáveis que regularizam as relações entre os atores. Por isso, alguns comportamentos são muito estáveis e difundidos, mesmo quando têm um caráter negativo como, por exemplo, o crime ou a corrupção. Tais comportamentos envolvem "redes interpessoais complexas, organizadas, de expectativas, comunicações, interesses e crenças encerradas na mesma matriz sócio cultural que encerra as estruturas legitimadas" (BUCKLEY 1971, p. 233).

As instituições fornecem os parâmetros para criação das organizações ou dos atores sociais, bem como as oportunidades que serão aproveitadas por eles. Também são as transmissoras dos comportamentos legítimos de uma sociedade qualquer. São formadas por símbolos, redes de comunicação e arranjos ecológicos que selecionam e canalizam determinadas percepções, ações e interações ao mesmo tempo em que excluem outras (BUCKLEY, 1971).

A perda de legitimidade não significa o colapso das formas institucionais vigentes. Buckley (1971) imagina quatro possiblidades. A primeira delas é a criação de novas instituições legítimas que refletirão um novo consenso social básico a respeito do desenvolvimento sustentável. A segunda possibilidade é a adaptação da sociedade e dos atores sociais a este modelo institucional que perde legitimidade e os obriga a negociações constantes. A terceira faz referência à desintegração social via conflito; e a quarta é a permanência das deficiências institucionais sem resultar no conflito ou no surgimento novas instituições mais legítimas.

Para Douglas (1998), as instituições são convenções que surgem a partir de um interesse comum que demanda coordenação. Tais convenções podem ser violadas ou ignoradas na medida em que indivíduos e atores retirem sua adesão a elas.

A perda de legitimidade das instituições e algumas de suas consequências sobre as relações entre atores serão abordadas na próxima seção.

\section{0 contexto mundial e seus impactos institucionais e organizacionais}

Para Beck (2003, p. 119), no modelo de desenvolvimento baseado na atuação do Estado e na grande empresa fordista como garantia de emprego e de geração de riqueza, o risco é incorporado pela sociedade através do controle e da delimitação de suas "consequências espaciais, temporais e sociais". A possibilidade de acidente na fábrica, por exemplo, é controlada pela identificação das possíveis causas gerais e da construção dos arranjos sociais adequados para prever ou compensar um potencial acidente.

Por outro lado, esse mesmo autor diz que a crescente "tecnização" e "economicização" (BECK, 2003, p. 149), isto é, o peso cada vez maior dos conhecimentos técnicos e econômicos como balizas das decisões na vida social corrói a possibilidade de se calcular as consequências não previstas das ações humanas. O resultado é a afirmação da consciência do risco que "abala a consciência desenvolvimentista" (BECK, 2003, p. 149). Por exemplo, a decisão de dado país de aumentar o uso da energia nuclear para produzir eletricidade incorre 
em risco de acidente nuclear que, caso ocorra, terá consequências imprevisíveis que não se restringirão ao país em questão.

Simultaneamente, a dificuldade em calcular ou prever as consequências das ações humanas estimula a participação, dado que cada ator interessado na energia nuclear - para utilizar o mesmo exemplo proposto por Beck - terá uma percepção diferente sobre aquelas consequências. Há os que são contra o uso deste tipo de energia temendo as consequências de seu uso para o meio ambiente ou para a segurança das populações. Outros, preocupados com o bem-estar material, advogam o seu uso porque aumenta a quantidade de energia disponível. Também há aqueles que, preocupados com a geração de emprego e de renda, concordam com o uso desse tipo de energia. O mesmo raciocínio é válido se se considerar uma indústria mais "inofensiva", como a automobilística ou as decisões e as ações voltadas ao desenvolvimento.

A consciência do risco se torna mais complexa se considerarmos a ecologia e a equidade, ou seja, se adicionarmos a ideia de sustentabilidade ao desenvolvimento mais imprevísisveis ficam as consequências das decisões de implantar, incentivar ou proibir determinada atividade econômica. Expõe, desse modo, os mais diversos interesses relativos ao desenvolvimento sustentável, mas ainda não levou as sociedades a um acordo social básico que permita prever e/ou compensar os eventuais acidentes futuros. As sociedades se adaptam permitindo uma multiplicidade de comportamentos e estimulando o surgimento de uma série de demandas sociais que, às vezes, são contraditórias.

Para Buckley (1971, p. 76), as sociedades são sistemas sócioculturais morfogênicos que elaboram e modificam continuamente suas estruturas para se adaptarem às novas condições externas ou internas. As estruturas sociais se tornam mais fluídas à medida que o processo de adaptação avança e permite o aumento dos "comportamentos alternativos franqueados aos componentes". O resultado é a maior autonomia das partes componentes do sistema e um novo equilíbrio, sempre provisório.

Tal situação, de acordo com Cerroni (1993), é um indício da crescente democratização das sociedades ocidentais que dificulta o consenso básico para encaminhar os problemas sociais. Preocupado com o mesmo problema, Bobbio (1996) diz que os atuais sistemas democráticos estimulam a participação, mas não conseguem harmonizar todos os interesses em uma vontade geral. Classifica, então, o aumento da participação como uma das promessas não cumpridas da democracia.

O aumento e a diversificação das demandas sociais tornam as sociedades cada vez mais ingovernáveis, dado que a capacidade de resposta das instituições não aumenta na mesma velocidade na qual as demandas surgem, o que pode levar a uma crise de legitimidade (BOBBIO, 1987).

Para Touraine (1998), vivemos um período de "desintitucionalização", isto é, as normas e as regras às quais os atores recorrem para pensar, agir e imaginar as possíveis ações e reações dos demais atores perdem legitimidade. Perda que implica em extinção, modificação ou estagnação das instituições vigentes, conforme apontado por Buckley (1971). 
A consciência do risco e o aumento da participação são indícios de que estamos vivendo um período no qual as instituições montadas ao final da Segunda Guerra Mundial perdem legitimidade, ao mesmo tempo em que as novas instituições ainda não são legítimas o bastante para ajudar a encaminhar os novos problemas sociais. Nesse ponto, qualquer uma das quatro situações previstas por Buckley (1971) pode ocorrer.

O desenvolvimento sustentável é a situação desejada por todos, mas a consciência dos riscos e o aumento da participação tornam as instituições menos legítimas e levam a um aumento dos conflitos e das incertezas que dificultam a construção de acordos para que a situação desejada se concretize. Dificuldades que são percebidas pelos atores sociais que atuam em diferentes escalas territoriais, tais como um país ou uma região, e misturam-se com as características específicas destes territórios.

\section{$4 \mathrm{O}$ contexto nacional e seus impactos institucionais e organizacionais}

No Brasil, a consciência do risco pode ser exemplificada por acontecimentos recentes. A regulamentação do uso dos transgênicos ${ }^{2}$, a votação do código florestal ${ }^{3}$ e a discussão, no âmbito do Estado de São Paulo, sobre a proibição das queimadas para a colheita da cana ${ }^{4}$ expuseram os mais diversos atores defendendo variados interesses, preocupados com os riscos econômicos, ambientais e sociais envolvidos em tais decisões. Da mesma maneira, a tendência de aumento da participação também pode ser encontrada aqui. Apesar de não se referirem diretamente ao desenvolvimento sustentável, a recente Lei de Acesso à Informação, a Lei de Responsabilidade Fiscal e o Orçamento Participativo são indícios da crescente participação.

No entanto, para utilizar os termos propostos por Buckley (1971), o sistema morfogênico brasileiro se adapta às influências mundiais de maneira particular. Aqui, a consciência do risco e o aumento de participação e as suas consequências são mediados por um sistema institucional no qual muitos comportamentos e ações são tidos como legais, mas não legítimos, enquanto outros são ilegais, mas legítimos.

\footnotetext{
${ }^{2}$ A Lei de Biossegurança (Lei 11.105/05) disciplina o plantio e a comercialização de organismos geneticamente modificados (OGM) e autoriza o uso de células-tronco de embriões humanos para pesquisas (Disponível em: http://www.planalto.gov.br/ccivil_03/_ato20042006/2005/lei/l11105.htm).

3 O Novo código Florestal (Lei 12.727/12) estabelece "normas gerais sobre a proteção da vegetação, áreas de Preservação Permanente e as áreas de Reserva Legal; a exploração florestal, o suprimento de matéria-prima florestal, o controle da origem dos produtos florestais e o controle e prevenção dos incêndios florestais, e prevê instrumentos econômicos e financeiros para o alcance de seus objetivos" (Disponível em: http://www.planalto.gov.br/ccivil_03/_Ato20112014/2012/Lei/L12727.htm).

4 "Uma série de ações judiciais movidas pelo Ministério Público Federal tem antecipado o fim da queima da cana-de-açúcar prevista para 2014 e 2017 em algumas regióes de São Paulo. A decisão afeta milhares de pequenos agricultores que argumentam ter mais cinco anos para se adequar ao protocolo de intenções firmado com o governo do Estado" (PEREIRA, 2012).
} 
DaMata (2006) explica tal característica a partir do costume brasileiro de classificar as leis em dois tipos: as que "pegam" e as que "não pegam". As leis que "não pegam" são aquelas "que a própria sociedade almeja e diz que quer, mas que, por contrariarem práticas sociais bem estabelecidas, 'não pegam', como, por exemplo, as que mandam ocupar cargos públicos somente por concurso" (DAMATA, 2006, p. 266).

O'Donnel (1998, p. 46) utiliza o termo "a incompletude do Estado" para descrever uma característica comum a muitos países da América Latina. Especialmente no Brasil, a desigualdade social e econômica estabelece quem obedece e quem não precisa obedecer à lei. A consequência é o afastamento do universalismo da lei e a poluição legal, isto é, há um acúmulo excessivo de leis na tentativa de ordenar as novas situações sociais, o que reforça a dicotomia entre as leis que "pegam" e as que "não pegam".

Uma possível explicação para as situações captadas por DaMata (2006) e O'Donnel (1998) é fornecida por Buarque de Holanda (1995). Para ele, os valores da família patriarcal têm um grande peso na formação da nossa sociedade. Tais valores incentivam as vontades e os interesses particulares e tornam difícil a distinção entre o público e o privado. Permitem a cultura da personalidade, ou seja, "o valor de um homem infere-se, antes de tudo, da extensão em que não precise depender dos demais [...]" (HOLANDA, 1995, p. 32). Tal cultura implica na desvalorização das atividades que pressupõem o trabalho em grupo, na falta de solidariedade social e na dificuldade de construir um acordo coletivo durável.

Os valores promovidos pela família patriarcal se opõem à construção de uma sociedade livre e igualitária e influenciaram de maneira decisiva a formação e o funcionamento do Estado brasileiro. Dentro dele, até os dias de hoje, predominam as vontades particulares e, por isso, pode ser classificado como patrimonialista, apesar de parecer burocrático, pois seu funcionamento privilegia interesses privados e as relações familiares (HOLANDA, 1995).

Para Weber (1999, p. 263),

o complexo patrimonial político não conhece nem o conceito de 'competência' nem o de 'autoridade administrativa' no sentido atual das palavras, e isto tanto menos quanto maior apropriação. A separação de assuntos oficiais e privados, patrimônio público e privado e a correspondente autoridade senhorial dos funcionários encontra-se apenas razoavelmente realizada no tipo arbitrário, diminuindo com o avanço do sistema de prebendas e apropriação.

$\mathrm{Na}$ vigência do complexo patrimonial político, o funcionário tal qual o senhor decide "caso a caso, isto é, segundo arbítrio e graça pessoal" (WEBER, 1999 p. 263). Quando o patrimonialismo contamina o Estado, "em vez da 'objetividade' burocrática e do ideal, baseado na vigência abstrata de um direito igual e objetivo, da administração sem 'considerações pessoais' rege o princípio oposto" (WEBER, 1999, p. 264).

As consequências do patrimonialismo são a sobrevivência das oligarquias regionais, a administração dos assuntos de caráter público a partir de critérios 
pessoais ou privados e a pouca preocupação com a eficiência e a eficácia da ação. Tais consequências podem ser encontradas nas várias esferas e níveis do Estado brasileiro.

Nesse caso, o exercício da política é tratado como um negócio que obedece à lógica do clã, isto é, as relações de interdepêndencia só se estabelecem entre membros do clã familiar ou político, fragilizando o tecido social e a cidadania (RODRIGUEZ, 2006). Nesse mesmo sentido, Paim (1998) diz que as forças políticas ligadas ao patrimonialismo percebem o Estado como um instrumento para a solução de seus problemas particulares e o ocupam "per se" (PAIM, 1998, p. 49). Ambos os autores caracterizam o patrimonialismo brasileiro com um componente modernizador, percebido principalmente nas tentativas de racionalização da esfera econômica.

Patrimonialismo e a "incompletude das leis" resultam em incerteza que permeia as relações econômicas, políticas e sociais. Rodriguez (2006) fala em "sociedade insolidária". Para Buarque de Holanda (1995), há tibieza das formas de organização que impliquem em solidariedade, tornando qualquer acordo coletivo não durável. A cooperação, nesse ambiente, é lentamente construída e muito frágil, pois é comum que muitos atores mobilizem seus recursos econômicos, políticos, cognitivos e gerenciais para obter vantagens do tipo free rider ou rent seeker.

Considerando a hipótese proposta por Olson (1999) sobre a cooperação dentro de grandes grupos, é possível supor que sem coerção ou a existência de incentivos individuais, os diversos atores não agirão para colaborar com a ação grupal, mesmo que ela seja de seu interesse. Nos grandes grupos, o esforço de um só indivíduo ou ator tem muito pouco peso. Sua contribuição é marginal para o grupo, mas ele será beneficiado se o grupo conseguir seu intento. Assim, é racional não agir, a não ser que seja coagido ou que receba um benefício individual.

No que diz respeito ao Brasil, é possível sustentar que existe um duplo incentivo para o comportamento oportunista. Por um lado, há incentivo para o oportunismo que os grandes grupos permitem conforme posto por Olson (1999). Por outro lado, há um reforço para o comportamento oportunista que vem das características institucionais da sociedade brasileira e pelo patrimonialismo do Estado. Nesse caso, a cooperação que surge entre atores sociais é limitada pela incerteza e gera acordos provisórios e parciais uma vez que as instituições sancionam como legítimos alguns comportamentos ilegais; ou como ilegítimos alguns comportamentos legais.

\section{0 contexto regional e as estruturas de governança}

Atualmente é cada vez mais legítima a preocupação em minimizar a poluição e a exaustão dos recursos naturais renováveis ou não renováveis, sentimento que contribui para a formação da ideia de desenvolvimento sustentável. No entanto, a sustentabilidade não diz respeito somente ao meio 
ambiente, há outros componentes envolvidos, tais como a economia e a equidade (FIGUEIREDO, 2012).

A noção de equidade faz emergir o problema da repartição entre os diversos segmentos sociais dos custos e dos benefícios decorrentes do funcionamento do sistema econômico. Para Müller (2001, p.127), a questão se coloca da seguinte maneira: "quem vai controlar e financiar as externalidades negativas sobre o meio ambiente e como se pode considerá-lo como um bem público?".

As externalidades negativas são as consequências do processo de produção ou do consumo de um bem ou serviço qualquer que causam prejuízo à sociedade de maneira geral. Tais danos são pagos por todos e não somente pelos produtores ou consumidores do bem cuja produção e consumo causam o dano.

Elas exemplificam a complexidade dos problemas que são expostos pela ideia da sustentabilidade, bem como expõem as alterações nos limites dos conflitos entre o público e o privado, ou seja, a melhor decisão privada pode resultar em externalidades negativas que serão pagas pelo conjunto da sociedade, que procura maneiras de ressarcimento, minimização ou neutralização destes custos, impondo leis contra a poluição, taxas sobre a produção e o consumo de certos bens, proibições de certas atividades e cotas de produção que, por sua vez, impactam as decisões privadas (FIGUEIREDO, 2012).

Recorrendo mais uma vez à ideia de risco proposta por Beck (2003), ou seja, a crescente dificuldade em se calcular as consequências das ações humanas a partir dos conhecimentos técnicos e econômicos disponíveis, as externalidades negativas podem ser consideradas como evidências do risco em âmbito regional, uma vez que é cada vez maior a brecha entre os recursos cognitivos de um ator qualquer para imaginar as consequências de certa ação voltada ao desenvolvimento e as prováveis reações dos demais atores.

Ainda considerando o âmbito regional, é possível supor que tal situação leve a um aumento do desejo de participação no processo de decisão, uma vez que cada ator social pensará e agirá para que seu modelo de desenvolvimento e de enfrentamento das externalidades negativas prevaleça. Assim, a influência do ambiente mundial, através da percepção do risco e do aumento da participação, é notada pelos atores regionais no encaminhamento das externalidades negativas.

Admitindo o raciocínio acima como pertinente, a cooperação é atraente para os atores regionais ao tornar o risco e o aumento da participação mais manejáveis. As estruturas de governança são inovações institucionais que tais atores montam para enfrentar os desafios do crescimento econômico e do desenvolvimento sustentável. A natureza da estrutura contribui para que as decisões que maximizam os resultados esperados por determinado ator sejam abandonadas e a adoção de decisões aceitáveis para os diversos atores envolvidos sejam incentivadas.

É nesse sentido que o grupo de pesquisa define as estruturas de governança como o 
conjunto de elementos institucionais, formalizados ou não, que estabelecem a regulação das relações entre atores públicos, privados e da sociedade civil (empresas, associações, sindicatos, poder público, ONGs) em torno de um planejamento ou projeto de desenvolvimento, ou mesmo na busca por resolver algum problema socioeconômico inédito em âmbito local, regional, nacional ou internacional (PIRES et al, 2011$, p. 8$)^{5}$.

A definição proposta pressupõe a necessidade de negociações de acordos e das necessárias revisões para a construção de ordens locais. Segundo Fligstein (2007), a construção ou revisão de uma ordem local é função da habilidade de um ator ou de um grupo de atores em induzir a cooperação dos demais. Entretanto, supondo a pertinência das ideias postas até aqui, mesmo este ator habilidoso encontrará dificuldades em assumir um papel preponderante na construção da ordem regional.

A consciência do risco e a maior participação combinados com a "incompletude das leis" e o patrimonialismo que legitimam "mais a lealdade pessoal e a hierarquia do que a igualdade e a obediência a normas impessoais e abstratas" (DAMATA, 2006, p. 271) geram uma contradição em âmbito regional: mais atores participam da busca pelo desenvolvimento e, ao invés de acordos sólidos, este aumento de participação resulta na construção de acordos parciais e provisórios.

Parece ser esse o caso das estruturas de governança identificadas pelo grupo de pesquisa: os comitês de bacia hidrográfica, os circuitos turísticos, as câmaras setoriais da agricultura e os arranjos produtivos locais (APLs). Todas funcionam parcialmente devido a três problemas principais: a sobreposição de estruturas de governança, isto é, um mesmo município faz parte de diferentes estruturas de governança que não se comunicam entre si; a participação pouco efetiva das secretarias estaduais; e a existência de assimetrias de informação. Tais problemas indicam fragilidade da cooperação entre os atores no âmbito das estruturas (PIRES et al, 2013).

Tais resultados parciais são frutos de um trabalho que começou com a identificação das estruturas de governança (Arranjos Produtivos Locais, Câmaras Setoriais, Circuitos Setoriais e Comitês de Bacia) que funcionam no interior do Estado de São Paulo, de acordo com as informações díponíveis em meios eletrônicos fornecidas pelas Secretarias Estaduais da Agricultura e Abastecimento e do Desenvolvimento. No entanto, nem todas as estruturas listadas funcionam de fato. Por exemplo, só o comitê de bacia Piracicaba, Capivari, Jundiaí (PCJ) funciona. Os demais comitês de bacia não são operacionais (PIRES et al, 2011).

Em seguida, inciou-se a coleta de dados secundários abrangendo o período entre 2003 a 2010, com o objetivo de entender a dinâmica econômica dos municípios pertencentes a uma dada estrutura. Utilizando informações do Instituto Brasileiro de Geografia e Estatística - IBGE, do Instituto de Economia Agrícola -

\footnotetext{
${ }^{5}$ Para economizar espaço e tornar a leitura mais fácil, utilizo a referência Pires, et al ao invés listar todos os autores envolvidos na feitura do projeto de pesquisa e dos relatórios de pesquisa citados neste artigo. Os nomes de todos os autores citados estão nas referências bibliográficas.
} 
IEA, da Relação Anual de Informações Sociais - RAIS e da Fundação Sistema Estadual de Análise Dados - Fundação SEADE, o grupo de pesquisa montou tabelas para cada município de cada estrutura de governança abrangendo as seguintes variáveis: população, Produto Interno Bruto PIB, PIB per capita, Valor Adicionado, trabalhadores ocupados, número e tamanho dos estabelecimentos e exportações e importações. Essas informações forneceram indícios sobre o processo de desconcentração espacial da produção, a evolução do perfil do emprego, as mudanças salariais, o padrão de concorrência entre as empresas e o grau de abertura comercial dos municípios (PIRES et al, 2011).

Outra tarefa foi a identificação e a caracterização da dinâmica política e institucional existentes no âmbito das estruturas de governança. Nesse caso, o grupo de pesquisa decidiu por três critérios. O primeiro deles foi estabelcer o perfil e evolução das organizações associativas de naturezas diversas para captar indícios dos mecanismos de participação (dados obtidos na RAIS). O segundo critério foi estabelecer o perfil dos partidos políticos presentes no poder executivo municipal para identificar as eventuais influências dos programas partidários sobre 0 funcionamento das estruturas (dados obtidos no Tribunal Superior Eleitoral - TSE). O terceiro critério foram as despesas municipais realizadas por função (econômica, política e gastos sociais) para evidenciar o papel dos municípios no financiamento do desenvolvimento municipal, a partir dos dados do IBGE (PIRES et al, 2011).

Por fim, o grupo de pesquisa optou por entrevistas semiestruturadas e pela participação nas reuniões (metodologia de grupos focais) para enfrentar o desafio metodológico de identificar quais atores participavam das estruturas, quais eram os hegemônicos e os processos de decisão (PIRES et al, 2011).

No caso dos comitês de bacia hidrográfica, os dados e informações coletados apontam, preliminarmente, para a baixa capacidade de resolução de conflitos, a ausência das secretarias estaduais que tratam de assuntos afins à questão da água, evidenciando a desconexão entre os recursos hídricos e os aspectos econômicos, políticos e sociais que existem no âmbito de dada bacia hidrográfica. Nesse caso, a cooperação necessária para o encaminhamento das externalidades negativas referentes ao uso da água ocorre de maneira parcial ou não acontece, o que permite especular sobre o quão sustentável é o desenvolvimento no âmbito dessas estruturas. Também vale destacar que apenas o comitê da bacia dos rios Piracicaba, Capivari e Jundiaí (comitê do PCJ) funciona de fato (PIRES et al, 2012; MANCINI, 2012) .

No caso dos circuitos turísticos, o grupo de pesquisa constatou a ênfase na parte econômica do desenvolvimento, evidenciada pela baixa representação dos atores sociais, que não estão diretamente ligados às atividades econômicas que acontecem no âmbito dessa estrutura, a sobreposição de ações dos governos federal e estadual e a falta de cooperação, mesmo entre as secretarias de governo

\footnotetext{
${ }^{6}$ O relatório de pesquisa de 2012 condensa o trabalho de alguns pesquisadores do grupo, que se dedicaram a estudar especificamente uma estrutura de governança identificada. Por este motivo, as referências ao relatório de 2012 são acompanhadas pela referência aos pesquisadores dedicados à estrutura em questão.
} 
estaduais que tratam de assuntos afins. (PIRES et al, 2012; FUINI, 2012; OTANI, et al, 2012).

As câmaras setoriais, no Estado de São Paulo, estão associadas à Secretaria de Agricultura e Abastecimento e são ligadas às cadeias produtivas do agronegócio. Sua função básica é apoiar a Secretaria de Agricultura e Abastecimento no que diz respeito às políticas públicas referentes ao setor. Os dados coletados apontam para dificuldades na comunicação entre as diversas câmaras setoriais e com as demais secretarias de governo, quando há necessidade de tratar de assuntos comuns (PIRES et al., 2012; SILVA, STAUDT, VERDI, 2009).

Em relação aos Arranjos Produtivos Locais - APLs, a pesquisa constatou a existência de vários em diferentes etapas de coordenação institucional e produtiva. Tais diferenças decorrem do tempo de formação do APL e do tipo de bem produzido. Tal como as outras estruturas identificadas pelo grupo de pesquisa, os dados coletados até agora sugerem a sobreposição de estruturas, as falhas de comunicação entre os atores participantes, especialmente as secretarias de governo e a predominância de ações pontuais, evidenciadas pela ausência de um plano para o futuro, ou seja, se desconsidera o quão sustentável no futuro será a atividade econômica que ensejou a criação do APL (PIRES et al., 2012; FUINI, 2012).

De maneira geral, as dificuldades encontradas no funcionamento das estruturas de governança identificadas pelo grupo de pesquisa em andamento fornecem indícios de que a cooperação é fragil entre os atores que delas participam. Fragilidade que pode ser explicada, nos termos deste trabalho, a partir das influências postas pelos contextos mundial e brasileiro sobre os atores que, de alguma maneira, estão interessados no desenvolvimento regional.

\section{Considerações finais}

Os atores sociais ou organizações são formados por indivíduos com um objetivo comum. São capazes de pensar e de agir de maneira estratégica, ou seja, de aproveitar as oportunidades que se apresentam em determinada situação. No entanto, seu pensamento e ação são constrangidos por um sistema de regras, as instituições, que determina o que é legítimo. North (1993) diz que as instituições são as regras do jogo, enquanto que os atores são os jogadores que objetivam vencer o jogo, burlando, em algumas ocasiões, o sistema de regras.

O mesmo raciocínio pode ser feito para descrever a busca pelo desenvolvimento sustentável regional. Tarefa complexa que exige cooperação dos atores interessados no tema. A demanda por cooperação é parcialmente atendida pelas estruturas de governança que funcionam de maneira a facilitar a construção de acordos entre atores sociais que defendem diferentes interesses.

No entanto, a demanda por cooperação é dificultada por algumas características postas pelos contextos mundial e brasileiro, que impactam os atores regionais que pensam e agem para o desenvolvimento sustentável. O contexto mundial evidencia a consciência do risco, isto é, o esgotamento do modelo de 
desenvolvimento baseado na atuação do Estado e da grande empresa de produção em massa. Indício desse esgotamento é a crescente incapacidade em lidar com as consequências não previstas das ações voltadas ao desenvolvimento.

A decisão de implantar ou incentivar dada atividade econômica terá consequências econômicas, sociais e ambientais não previstas que serão combatidas ou apoiadas em função dos interesses dos vários atores sociais preocupados com a atividade em questão. Nesse sentido, a consciência do risco se traduz em uma maior participação, ou seja, mais atores procuram influenciar os rumos relativos ao desenvolvimento sustentável de acordo com seus interesses, o que compromete a legitimidade das instituições que não conseguem dar vazão ao aumento das demandas sociais associado à crescente diversidade de interesses.

Já o contexto brasileiro é caracterizado pela "incompletude das leis", pela distinção entre as leis que "pegam" e as que "não pegam"; e pelo patrimonialismo do Estado, que permite ao governante tratar de assuntos públicos a partir de critérios privados, sem maior preocupação com a eficácia da ação pública estatal. As três características fornecem indícios de que a estrutura institucional do país legitima alguns comportamentos e ações ilegais, o que dificulta a cooperação.

Supondo que, regionalmente, o encaminhamento das externalidades negativas evidencia a consciência do risco, uma vez que os atores regionais têm limitados recursos cognitivos, políticos, econômicos e gerenciais que os habilitem a examinar e prever as consequências de suas ações; então tal situação estimula a participação, uma vez que os atores pensarão e agirão para que aquele encaminhamento atenda, na medida do possível, aos seus interesses. Maior participação torna mais difícil a construção de um consenso inicial que permita a cooperação. Dificuldade acentuada pelas características postas pelo contexto brasileiro.

Os problemas encontrados pelo grupo de pesquisa fornecem indícios da dificuldade em cooperar no âmbito das estruturas de governança estudadas. Algumas delas existem apenas no papel, outras não são plenamente operacionais e há aquelas que enfatizam apenas o aspecto econômico do desenvolvimento sustentável. Também é comum que dado município ou secretarias de governo participem de mais de uma estrutura de governança sem se comunicar entre si, o que compromete a eficácia da ação estatal no âmbito das estruturas estudadas.

As informações colhidas até agora parecem indicar que as estruturas de governança, criadas para facilitar a cooperação entre atores que buscam o desenvolvimento regional, não encaminham as dificuldades associadas a estas tarefas, apenas as acomodam em acordos temporários que não geram uma maior densidade das relações sociais.

\section{REFERÊNCIAS}

BECK, U. 2003. Liberdade ou capitalismo: Ulrich Beck conversa com Johannes Willms, São Paulo: Editora UNESP, 2003. 158 p. 
BOBBIO, N. O futuro da democracia. Uma defesa das regras do jogo. Rio de Janeiro: Paz e Terra, 1996. 171 p.

BOBBIO, N. Estado, governo, sociedade: Por uma teoria geral da política. Rio de Janeiro: Paz e Terra, 1987. 173 p.

BRASIL. Presidência da República. Casa Civil. Lei no. 11.105, de 24 de março de 2005. Brasília, DF. Disponível em: <http://www.planalto.gov.br/ccivil_03/_ato20042006/2005/lei/l11105.htm >Ac esso em 01/10/2013.

BRASIL. Presidência da República. Casa Civil. Lei no. 12.727, de 17 de outubro de 2012. Brasília, DF. Disponível em: <http://www.planalto.gov.br/ccivil_03/_Ato20112014/2012/Lei/L12727.htm > . Acesso em 01/10/2013.

BUCKLEY, W. A sociologia e a moderna teoria dos sistemas. São Paulo: Cultrix; Editora da USP, 1971. 307 p.

CATALÀ, J. P. i. Administración pública y desarrollo en América Latina, In: // Congresso Interamericano del CLAD sobre la Reforma del Estado y de la Administración Pública, 1997, Venezuela. Anais. Venezuela: CLAD, 1997, p. 9 48.

CERRONI, U. Política: métodos, teorias, processos, sujeitos, instituições $e$ categorias. São Paulo: Brasiliense, 1993. 222 p.

DAMATA, R. 2006 Desafios do milênio: o papel e a razão da sociedade. In: 0 dever do Estado, Porto Alegre: IEE, 2006, p. 263 - 274.

DE BRUYNE, P.; HERMAN, J.; SCHOUTHEETE, M. Dinâmica da pesquisa em ciências sociais. Rio de Janeiro: Livraria Francisco Alves Editora, 1997. 251 p.

DOUGLAS, M. Como as instituições pensam. São Paulo: Editora Universidade de São Paulo, 1998. 144 p.

DUBAR, C. Agente, ator sujeito, autor: do semelhante ao mesmo. In: Primeiro Congresso da Associação Francesa de Sociologia, 2004, Paris. Disponível em: $<$ http://pt.scribd.com/doc/94289553/DUBAR-Claude-Agente-ator-sujeito autorAtor-agente-autor-do-semelhante-ao-mesmo-2004. (Acesso em 21 mar. 2011).

FIGUEIREDO FILHO, W.B. Estruturas de governança regionais, desenvolvimento sustentável e legitimidade: notas para a construção de um esquema de referência. Revista de desenvolvimento econômico - Universidade de Salvador, Salvador, n. 26, p. 136-144, dez. 2012.

FLIGSTEIN, N. 2007. Habilidade social e teoria dos campos. RAE-FGV, Rio de Janeiro, n. 2, p. $61-80$, abr./jun. 2007. 
FUINI, L. L. Compreendendo a governança territorial e suas possibilidades: Arranjos Produtivos Locais (APL) e Circuitos turísticos. Interações, Cuiabá, UCDB, v. 13, n.1, p. 93-104, jan./jun. de 2012.

HOLANDA, S.B. Raízes do Brasil. São Paulo: Cia das Letras, 1995. 220 p.

MANCINI, R.F. As governanças territoriais nas bacias hidrográficas dos rios Piracicaba, Capivari e Jundiaí: processos, desenvolvimento e limites de cooperação. Tese (doutorado). Universidade Estadual Paulista, Instituto de Geociências e Ciências Exatas: Rio Claro, 2012.

MARQUES, E.C. Redes sociais e poder no Estado brasileiro. Aprendizado a partir das políticas urbanas. RBCS, São Paulo, nº 60, p. 15-41, fev. 2006.

MATUS, C. Adeus, senhor Presidente. Governantes governados. São Paulo: Edições Fundap, 1996. 376 p.

MÜLLER, G. Desenvolvimento sustentável: notas para a elaboração de um esquema de referência. In: BECKER, D.F (Org). Desenvolvimento sustentável: necessidade e/ou possibilidade. Santa Cruz do Sul: EDUNISC, 2001, p. 117-138.

NORTH, D. C. Instituciones, cambio institucional y desempeño econômico. México D.F.: Fondo de Cultura Econômica, 1993. 190 p.

O'DONNEL, G. 1998. Poliarquias e a (in)efetividade da lei na América Latina. Novos Estudos CEBRAP, São Paulo, n. 51, p. 37-61, jun. 1998.

OLSON, M. A lógica da ação coletiva: os benefícios públicos e uma teoria dos grupos sociais. São Paulo: Editora da Universidade de São Paulo, 1999. 208 p.

OTANI, M. et al. Circuito das frutas paulistas: caracterização socioeconômica. Revista Informações Econômicas, São Paulo, n.3, p. 50-64, maio/jun. 2012.

SILVA, R.O.; STAUDT, N.; VERDI, A.R. Câmaras setoriais do agronegócio paulista: o novo papel do Estado junto à sociedade civil. Informações Econômicas, São Paulo, n.4, p. 17-29, abr. 2009.

PAIM, A. A querela do estatismo. Brasília: Senado Federal, 1998. 200 p.

PEREIRA, R. Justiça antecipa o fim da queima de cana em SP. Estadão.com.br, São Paulo, $21 \quad$ out. 2012. Disponível em: <http://www.estadao.com.br/noticias/impresso, justica-antecipa-fim-de-queimada-cana-em-sp-,948669,0.htm>. Acesso em 01/10/2013.

PIRES, E (coord.); FUINI, L.L.; MANCINI, R.F.; OTANI, M; SOUZA, M.C.; STAUD, N.; VERDI, A.R. As modalidades de governança territorial no Estado de Estado de São Paulo: projeto de pesquisa. Rio Claro: UNESP, 2011. 20 p. 
PIRES, E. (coord.); FIGUEIREDO FILHO, W.B.; FUINI, L.L.; MANCINI, R.F.; OTANI, M; SOUZA, M.C.; STAUD, N.; VERDI, A.R. As modalidades de governança territorial no Estado de Estado de São Paulo: relatório de pesquisa. Rio Claro: UNESP, 2012. 22 p.

PIRES, E. (coord.); FIGUEIREDO FILHO, W.B.; FUINI, L.L.; MANCINI, R.F.; OTANI, M; SOUZA, M.C.; STAUD, N.; VERDI, A.R. As modalidades de governança territorial no Estado de Estado de São Paulo: relatório de pesquisa. Rio Claro: UNESP, 2013. 16 p.

RODRIGUEZ, R.V. Patrimonialismo e a realidade latino-americana. Rio de Janeiro: Documenta histórica, 2006. 111 p.

TOURAINE, A. Podemos viver juntos? Iguais e diferentes. Petrópolis: Vozes, 1998. $387 \mathrm{p}$.

WEBER, M. Dominação patriarcal e dominação patrimonial, in: Economia $e$ sociedade: fundamentos da sociologia compreensiva. Brasília: Editora Universidade de Brasília; São Paulo: Impressa Oficial do Estado de São Paulo, 1999. p. $233-287$.

Submetido em $21 / 10 / 2013$

Aprovado em 05/05/2015

Sobre o autor

Wilson Bento Figueiredo Filho

Doutor em Geografia, Professor Adjunto II da Academia da Força Aérea (AFA) em Pirassununga e pesquisador do grupo de pesquisa "Estruturas de governança e desenvolvimento territorial", que desenvolve suas atividades no Departamento de Planejamento Regional da UNESP - campus Rio Claro sob a coordenação do Prof. Dr. Elson Luciano Pires.

Endereço: Estrada de Aguaí, s/no, Campo Fontenelle. 13643-000 - Pirassununga, SP - Brasil

E-mail: wilson_figueiredo@ig.com.br 